\title{
Atividade antibacteriana do óleo essencial de Melaleuca alternifolia frente a isolados multirresistentes produtores de ESBL e KPC causadores de infecções hospitalares
}

\author{
Alessandra Gioppo \\ Vilmair Zancanaro \\ Emyr Hiago Bellaver * \\ Universidade Alto Vale do Rio do Peixe - UNIARP \\ Rua Victor Baptista Adami, 800, CEP 89.500-199, Caçador - SC, Brasil \\ * Autor para correspondência \\ hi.agobellaver@hotmail.com
}

Submetido em 05/03/2019

Aceito para publicação em 26/06/2019

\section{Resumo}

A produção de $\beta$-lactamases por bactérias Gram-negativas é a principal forma de resistência aos antimicrobianos, com destaque para as $\beta$-lactamases de amplo espectro (ESBL) e de carbapenemases (KPC). Como forma de controle dos microrganismos multirresistentes, os metabólitos secundários vegetais são objeto de estudo para o desenvolvimento de novos medicamentos. O óleo essencial de Melaleuca alternifolia (OTT) possui efeito antifúngico, anti-inflamatório e antimicrobiano, este último atribuído principalmente aos terpenos presentes na sua composição. Este trabalho objetivou determinar o potencial antimicrobiano de emulsões de OTT frente a isolados de Escherichia coli e Klebsiella pneumoniae multirresistentes produtores de ESBL e carbapenemases responsáveis por infecções hospitalares. A atividade antibacteriana das emulsões do óleo essencial foi determinada através da concentração inibitória mínima (CIM), pelos métodos de macrodiluição em tubos, Spot-on-the-lawn, difusão por poços em ágar e disco-difusão. As concentrações que inibiram o crescimento bacteriano variaram entre $0,25 \%$ a $1,5 \%$ para as diferentes metodologias aplicadas. As emulsões do óleo essencial de Melaleuca alternifolia inibiram o crescimento das bactérias multirresistentes, conforme observado no método da macrodiluição em tubo e Spot-on-the-lawn. A cepa hospitalar de Escherichia coli produtora de ESBL mostrou-se a cepa mais sensível, o que permite descrever o potencial antibacteriano do óleo, que deverá ser avaliado em estudos futuros como agente de controle.

Palavras-chave: Betalactâmicos; Carbapenêmicos; Escherichia coli; Klebsiela pneumonia

\section{Abstract}

Essential oil of Melaleuca alternifolia is effective against ESBL- and KPC-producing multiresistant isolates that cause hospital infections. The production of $\beta$-lactamases by Gram-negative bacteria is the main form of antimicrobial resistance, especially broad-spectrum $\beta$-lactamases (ESBL) and carbapenemases (KPC). To control multiresistant microorganisms, secondary plant metabolites are being studied to develop new drugs. The essential oil of Melaleuca alternifolia (OTT) has antifungal, anti-inflammatory and antimicrobial effects, of which the latter is attributed mainly to terpenes present in its composition. This work aimed to determine 
the antimicrobial potential of OTT emulsions against ESBL- and KPC- producing, multiresistant isolates of Escherichia coli and Klebsiella pneumoniae isolates responsible for nosocomial infections. The antibacterial activity of the essential oil emulsions was determined by the minimum inhibitory concentration (MIC) using the following methods: tube macrodilution, spot-on-the-lawn, agar diffusion and disk diffusion. Concentrations that inhibited bacterial growth ranged from $0.25 \%$ to $1.5 \%$ for the different methodologies applied. The essential oil emulsions of Melaleuca alternifolia inhibited the growth of multiresistant bacteria, as observed for the tube macrodilution and spot-on-the-lawn methods. The ESBL-producing Escherichia coli proved to be the most sensitive strain to describe the antibacterial potential of the oil, which should be evaluated in future studies as a control agent.

Key words: Betalactamases; Carbapenemases; Escherichia coli; Klebsiela pneumonia

\section{Introdução}

Substâncias antimicrobianas são aquelas que exercem ação bactericida ou bacteriostática na proliferação de microrganismos e agentes infecciosos, com o intuito de prevenir ou de curar uma infecção (BRASIL, 2011). Porém, através de um mecanismo intrínseco, por vezes uma cepa bacteriana pode produzir linhagens geneticamente menos susceptíveis aos fármacos antimicrobianos, conferindo-lhes resistência e permitindo a sua sobrevivência (PEREIRA; OLIVEIRA, 2016).

Um microrganismo pode ser considerado resistente quando ele, ainda que na presença de uma droga antibiótica na mesma concentração inibitória daquela atingida na via sérica, continua a apresentar um crescimento in vitro (RODRIGUES et al., 2018).

Estudos revelam que em torno de $70 \%$ das bactérias causadoras de infecções hospitalares apresentam resistência a pelo menos um dos antimicrobianos comumente utilizados para o tratamento dos pacientes. A ocorrência de infecções hospitalares eleva os períodos de internamento e aumenta os custos, além de estarem diretamente relacionadas às taxas de mortalidade (ABELA; BORG, 2012; NUNES et al., 2014; ALVES et al., 2017).

Numa tentativa de evidenciar o problema de multirresistência de microrganismos, sobretudo no âmbito hospitalar, a Organização Mundial da Saúde (OMS) publicou a primeira lista mundial de agentes patogênicos prioritários multirresistentes, com o intuito de direcionar as pesquisas e o desenvolvimento de novas drogas antibióticas, enfatizando também o uso controlado e racional desses medicamentos. No topo dessa lista encontram-se os patógenos considerados críticos e que frequentemente estão associados às infecções hospitalares, entre os quais estão os microrganismos Gram-negativos da família Enterobacteriaceae (OPAS/ OMS, 2017).

Entre as bactérias Gram-negativas, a produção de $\beta$-lactamases é a principal forma de resistência aos antimicrobianos, com destaque para as Betalactamases de Espectro Ampliado (ESBL), que fazem hidrólise da cadeia oximino-betalactamase das cefalosporinas de ampla cobertura, e para as produtoras de carbapenemases (KPC). Estas últimas possuem genes que lhes conferem resistência a todos os agentes betalactâmicos como as cefalosporinas, penicilinas, monobactâmicos e, inclusive, a carbapenêmicos, ocorrendo principalmente nos gêneros Klebsiella, Enterobacter, Escherichia, Serratia, Citrobacter, Salmonella, Proteus e Morganella (BROLUND, 2014; SEIBERT et al., 2014; DOI et al., 2017).

Os compostos vegetais com propriedades farmacológicas são constantemente objetos de estudo para o desenvolvimento de novas opções de medicamentos (DUTRA et al., 2016). Essa é uma tendência estimulada pela OMS, que reforça a necessidade de priorizar pesquisas que levem em conta a efetividade e a segurança do uso de práticas complementares para promoção da saúde das populações (DAMATO, 2015).

Na busca por novas matérias-primas que preencham as lacunas que a multirresistência produz, diversos estudos buscam opções de antimicrobianos que incluem metabólitos secundários de plantas aromáticas, incluindo 
o uso de óleos essenciais (OE) e os compostos químicos voláteis (GNATTA, 2012; LEAL, 2013).

Uma vasta diversidade de OE oferece propriedades bactericidas, tanto contra bactérias Gram-positivas quanto para Gram-negativas, e entre eles encontra-se o OE de Melaleuca alternifolia, ou Óleo de Tea Tree (OTT), extraído por arraste a vapor de um tipo de árvore que leva o mesmo nome, pertencente à família Myrtaceae (LEE et al., 2013).

O aumento do número de mortes devido às complicações decorrentes de microrganismos multirresistentes concomitantemente com o desenvolvimento de novas pesquisas para elaboração de fármacos que venham a erradicar estes isolados, desperta o interesse no desenvolvimento de novas soluções para conter a disseminação de tais microrganismos. Assim, este trabalho teve como objetivo determinar o potencial antimicrobiano do OTT frente a isolados multirresistentes causadores de infecção hospitalar, determinando a concentração inibitória mínima do composto por variadas metodologias.

\section{Material e Métodos}

\section{Obtenção e crescimento dos isolados multirresistentes}

A obtenção dos microrganismos se deu através do isolamento de sítios anatômicos colonizados de pacientes acometidos por infecções em ambiente hospitalar. As amostras de urina e swab retal foram coletadas em um hospital de grande porte e referência em transplantes hepáticos e de medula óssea na cidade de Curitiba - PR.

Os isolados de Escherichia coli ESBL, Klebsiella pneumoniae ESBL e $K$. pneumoniae KPC foram colocados para crescimento em ágar Macconkey por $24 \mathrm{~h}$ a $37^{\circ} \mathrm{C}$. Os isolados E. coli ATCC 25922 e K. pneumoniae ATCC 13883 foram crescidos nas mesmas condições. As colônias puras foram diluídas em solução salina $0,9 \%$ e a leitura foi realizada em espectrofotômetro na absorbância de $625 \mathrm{~nm}$ para obter a suspensão bacteriana na concentração de $1,5 \times 10^{8} \mathrm{UFC} / \mathrm{mL}$. Essa concentração bacteriana foi utilizada em todos os métodos.

\section{Obtenção do OTT e preparado das emulsões}

Utilizou-se o óleo essencial de Melaleuca alternifolia da empresa Harmonie Aromaterapia Ltda., com atestado de origem Australiana, pureza e níveis dos componentes comprovados pelo laudo de análise química de cromatografia gasosa de alta resolução. Para as análises propostas foram preparadas emulsões do óleo a $0,25,0,5,0,75,1,0$ e $1,5 \%$ utilizando $5 \mu \mathrm{L}$ de Tween 80 como agente emulsificante em água destilada qsp 2,2 mL (NASCIMENTO et al., 2007). As emulsões foram agitadas em vórtex, a temperatura ambiente.

\section{Determinação da concentração inibitória mínima}

\section{Técnica de macrodiluição}

Foram preparados tubos de ensaio contendo 800 $\mu \mathrm{L}$ de caldo BHI, $200 \mu \mathrm{L}$ do microrganismo e $1 \mathrm{~mL}$ da emulsão de OTT, seguindo a metodologia proposta por Ostrosky et al. (2008) com algumas modificações. Como controle positivo de crescimento foi utilizado $800 \mu \mathrm{L}$ de caldo BHI com $200 \mu \mathrm{L}$ do microrganismo, e para o controle de inibição foi adicionada a Polimixina $0,5 \mu \mathrm{g} /$ $\mathrm{mL}$. O emulsificante também foi avaliado assegurando não possuir ação bactericida frente às cepas testadas. Os experimentos foram incubados por $24 \mathrm{~h}$ a $37^{\circ} \mathrm{C}$ e as análises foram realizadas em triplicata, para cada uma das concentrações.

\section{Determinação da CIM}

Ao término de $24 \mathrm{~h}$, os tubos com o caldo visivelmente límpidos foram semeados em ágar MuellerHinton (MH) para contagem de colônias e determinação da CIM. Os testes foram realizados em triplicata e a CIM foi considerada como a última concentração de OTT capaz de inibir em sua totalidade o crescimento bacteriano (NASCIMENTO et al., 2007).

\section{Spot-on-the-lawn}

A técnica descrita por Daifas et al. (2004), com algumas modificações, foi empregada para determinação 
da CIM. Através do método de dispersão, as suspensões bacterianas foram semeadas em placa contendo ágar $\mathrm{MH}$ e então, após secagem das placas, alíquotas de $10 \mu \mathrm{L}$ das diversas concentrações de OTT foram dispensadas pontualmente. Após completa absorção das emulsões, as placas foram incubadas a $37^{\circ} \mathrm{C}$ por $24 \mathrm{~h}$. Os halos de inibição do crescimento bacteriano foram expressos em milímetros $(\mathrm{mm})$. As análises foram realizadas em triplicata e os resultados foram expressos pela média aritmética e pelo desvio padrão dos três ensaios.

\section{Difusão por poços em ágar MH}

As suspensões bacterianas foram semeadas em ágar MH pela técnica de distensão. Após a completa secagem da placa, poços de $4 \mathrm{~mm}$ de diâmetro foram realizados no ágar e $100 \mu \mathrm{L}$ das emulsões de OTT nas diversas concentrações foram adicionadas aos poços. As placas seguiram para refrigeração, para que houvesse difusão do material sem que ocorresse crescimento bacteriano, e, então, foram encubadas a $37^{\circ} \mathrm{C}$ por $24 \mathrm{~h}$. As análises foram realizadas em triplicata e os halos de inibição de crescimento bacteriano foram expressos em milímetros (mm) (SILVA et al., 2010).

\section{Disco-difusão (método de Kirby-Bauser)}

Seguindo as recomendações do CLSI (2017), as placas com ágar MH foram semeadas com a suspensão bacteriana e receberam discos de papel filtro de $6,5 \mathrm{~mm}$, impregnados com $15 \mu \mathrm{L}$ das diversas concentrações das emulsões de OTT e então incubados a $37^{\circ} \mathrm{C}$ por 24 h. Após esse período, os halos de inibição foram observados e expressos em milímetros ( $\mathrm{mm})$. As análises foram realizadas em triplicata. Para o controle de inibição negativo foram utilizados discos estéreis $6,5 \mathrm{~mm}$ enquanto para o controle positivo foi utilizado Polimixina 300 UI para os isolados sensíveis.

\section{Análise estatística}

O tratamento estatístico foi realizado pela análise de variância (ANOVA), com $\mathrm{p}<0,05$ para grau de significância, seguida do teste de comparação múltipla de Tukey desenvolvido com o Software GraphPad Prism versão 5.0.

\section{Resultados}

As propriedades antimicrobianas dos óleos essenciais residem, sobretudo, no seu grupo terpeno. Nas plantas medicinais, o conteúdo total ou as proporções relativas dos terpenos pode variar entre plantas da mesma espécie devido a diversos fatores ambientais, além de variações genéticas intraespecíficas da espécie vegetal, que podem alterar os teores dos princípios ativos presentes no óleo, incluindo os aromáticos (GOBBONETO; LOPES, 2007; SEFIDKON et al., 2007).

A análise cromatográfica do óleo essencial comercial de Melaleuca alternifolia, fornecida pela empresa, apresentou $73 \%$ de terpenos; sendo os compostos majoritários identificados como: terpinen4-ol (45\%), $\gamma$-terpineno (19,5\%), $\alpha$-terpineno $(9,1 \%)$, $\alpha$-terpineol $(4,3 \%)$, terpinoleno (3,5\%), p-cimeno $(2,6 \%), \alpha$-pineno $(2,2 \%)$, viridiflorino $(2,1 \%)$, limoneno $(1,9 \%)$, cis-calameno $(1,5 \%), \beta$-gurjuneno $(1,4 \%)$, 1,8-cineol $(1,3 \%)$ e outros compostos minoritários identificados como: $\alpha$-thujeno $(0,6 \%)$, sabineno $(0,5 \%)$, $\beta$-pineno $(0,6 \%)$, mirceno $(0,6 \%), \alpha$-felandreno $(0,5 \%)$ e outros $(2,8 \%)$.

A concentração inibitória mínima das emulsões foi testada pela técnica da macrodiluição em tubo, e a menor concentração que inibiu o crescimento de todos os microrganismos foi a de $0,25 \%$ de OTT (Tabela 1 ). Nascimento et al. (2007) relatam que a formação de uma suspensão com turbidez ao se utilizar óleos essenciais pode ocorrer, ocasionada por uma diluição insuficiente dos compostos testados, interferindo na análise visual da eficácia do óleo.

Por outro lado, na análise das placas onde a metodologia Spot-on-the-lawn foi empregada (Tabela 2), observou-se a formação de halos de inibição do crescimento das bactérias nas concentrações de $0,25 \%$ até $1,5 \%$ de emulsão de OTT. Observou-se que a bactéria K. pneumoniae KPC não apresentou grande variação dos halos, sendo $4 \mathrm{~mm}$ observado na concentração de $0,25 \%$ e $6 \mathrm{~mm}$ na máxima concentração testada. Sugere-se que a morfologia das colônias produzidas pelo gênero Klebsiella, com seu aspecto mucoide, pode ser um fator prejudicial na visualização de halos de inibição e a hipótese levantada é confirmada por Aires et al. (2017). 
TABELA 1: Determinação da concentração inibitória mínima em caldo e placa frente a isolados de $\beta$-lactamases de amplo espectro (ESBL) e de carbapenemases e (KPC) expostos a diversas concentrações de óleo essencial de Melaleuca alternifolia.

\begin{tabular}{|c|c|c|c|c|}
\hline \multirow[b]{2}{*}{ Isolados } & \multicolumn{4}{|c|}{ Metodologias aplicadas } \\
\hline & Macrodiluição & Spot-on-the-lawn & $\begin{array}{l}\text { Difusão por poços } \\
\text { em ágar MH }\end{array}$ & Disco-difusão \\
\hline E. coli $\mathrm{ESBL}$ & $0,25 \%^{\mathrm{a}}$ & $0,25 \%{ }^{\mathrm{a}}$ & $0^{\mathrm{b}}$ & $0^{\mathrm{b}}$ \\
\hline E. coli ATCC 25922 & $0,25 \%^{\mathrm{a}}$ & $0,25 \%^{\mathrm{a}}$ & $0^{\mathrm{b}}$ & $0^{\mathrm{b}}$ \\
\hline K. pneumoniae $\mathrm{ESBL}$ & $0,25 \%^{\mathrm{a}}$ & $1,0 \%^{\mathrm{b}}$ & $0^{c}$ & $0^{c}$ \\
\hline K. pneumoniae KPC & $0,25 \%{ }^{\mathrm{a}}$ & $0,25 \%{ }^{\mathrm{a}}$ & $0^{\mathrm{b}}$ & $0^{\mathrm{b}}$ \\
\hline K. pneumoniae ATCC 13883 & $0,25 \%^{\mathrm{a}}$ & $0,25 \%^{\mathrm{a}}$ & $0^{\mathrm{b}}$ & $0^{\mathrm{b}}$ \\
\hline
\end{tabular}

MH: Ágar Mueller Hinton; Ao se comparar as metodologias utilizadas para determinação da CIM, letras diferentes subscritas nas identificações das concentrações aplicadas nos tratamentos em relação ao patógeno apresentam diferenças estatísticas pelo teste de Tukey $(\mathrm{p}>0,05)$.

TABELA 2: Medidas dos halos de inibição (mm) formados pelo óleo essencial de Melaleuca alternifolia em placas de ágar MH impregnadas conforme metodologia Spot-on-the-lawn contra isolados multirresistentes.

\begin{tabular}{lccccc}
\multirow{2}{*}{ Isolados } & \multicolumn{5}{c}{ Concentrações $(\mathbf{\%}) /$ Halos $(\mathbf{m m})$} \\
\cline { 2 - 6 } & $\mathbf{0 , 2 5 \%}$ & $\mathbf{0 , 5 \%}$ & $\mathbf{0 , 7 5 \%}$ & $\mathbf{1 \%}$ & $\mathbf{1 , 5 \%}$ \\
\hline E. coli ESBL & $8 \pm 0,7^{\mathrm{a}}$ & $8 \pm 0,1^{\mathrm{a}}$ & $8 \pm 1,4^{\mathrm{a}}$ & $9 \pm 2,8^{\mathrm{a}}$ & $10 \pm 1,4^{\mathrm{a}}$ \\
\hline E. coli ATCC 25922 & $7,3 \pm 0,2^{\mathrm{a}}$ & $7,5 \pm 0,3^{\mathrm{a}}$ & $7,3 \pm 0,2^{\mathrm{a}}$ & $8,1 \pm 0,4^{\mathrm{a}}$ & $8,6 \pm 0,1^{\mathrm{a}}$ \\
\hline K. pneumoniae ESBL & $0^{\mathrm{a}}$ & $0^{\mathrm{a}}$ & $0^{\mathrm{a}}$ & $7 \pm 1,4^{\mathrm{b}}$ & $9 \pm 0,7^{\mathrm{b}}$ \\
\hline K. pneumoniae KPC & $4 \pm 0,7^{\mathrm{a}}$ & $5 \pm 0,1^{\mathrm{a}}$ & $6 \pm 0,1^{\mathrm{a}}$ & $6 \pm 0,2^{\mathrm{a}}$ & $6 \pm 0,1^{\mathrm{a}}$ \\
\hline K. pneumoniae ATCC 13883 & $0^{\mathrm{a}}$ & $5 \pm 0,3^{\mathrm{b}}$ & $4,6 \pm 0,3^{\mathrm{b}}$ & $4,8 \pm 0,2^{\mathrm{b}}$ & $5,3 \pm 0,2^{\mathrm{b}}$ \\
\hline
\end{tabular}

\pm desvio padrão. Ao se comparar as concentrações das emulsões empregadas na metodologia analisada, letras diferentes subscritas nas identificações das concentrações aplicadas nos tratamentos em relação ao patógeno apresentam diferenças estatísticas pelo teste de Tukey $(\mathrm{p}>0,05)$.

Seguindo para Tabela 2, na metodologia Spot-onthe-lawn, E. coli ESBL apresentou halos de inibição entre $8 \mathrm{~mm}$ para a concentração $0,25 \%$ a $10 \mathrm{~mm}$ para a concentração $1,5 \%$. Todos os testes foram realizados em triplicata e os resultados foram expressos pela média aritmética e desvio padrão dos três ensaios. As análises das cepas padrões pela mesma metodologia não diferiu estatisticamente nos ensaios $(p>0,05)$.

Nas placas onde se empregou a técnica de difusão por poços em ágar MH não houve formação de halos que pudessem ser visualizados (Tabela 1). Possivelmente, a alta viscosidade do óleo é um fator importante a ser considerado no emprego desta técnica.

\section{Discussão}

A International Organization for Standardization (2017), pela normativa ISO 4730:2017, preconiza que a composição do OTT deve conter mais de $30 \%$ do seu biomarcador, o terpinen-4-ol, menos de $15 \%$ de 1,8 -cineol, entre $10 \%$ a $28 \%$ de $\gamma$-terpineno e $0,5 \%$ a $12 \%$ de p-cimeno. Através da análise obtida constatase, assim, a pureza do óleo essencial comercial para o estudo.

A ação antimicrobiana do OTT está relacionada à sua intervenção na camada de fosfolipídios da membrana celular bacteriana devido ao seu caráter lipofílico, promovendo um aumento da permeabilidade da membrana citoplasmática (BEZERRA CRISPIM; DE LACERDA, 2014; SARTO; JUNIOR, 2014). Por conseguinte, ocorre a perda de elétrons e a 
coagulação dos constituintes plasmáticos, provocando um extravasamento do material intracelular, em especial íons de potássio. Como consequência de todo este processo, tem-se a inibição da respiração e a quebra da homeostase celular (GE; GE, 2016).

Embora a disco-difusão para avaliação da atividade antibacteriana seja a metodologia de primeira escolha na maioria das pesquisas utilizando óleos essenciais, no presente estudo a avaliação das placas não revelou a presença de halos de inibição. Na abordagem sobre os métodos empregados para a avaliação da atividade antimicrobiana dos óleos essenciais, Takarada et al. (2004) e Nascimento et al. (2007) fazem referência à utilização da técnica de disco-difusão, e sugerem que a alta viscosidade da emulsão e a formação de micelas pelo uso do emulsificante Tween podem interferir durante a impregnação dos discos de papel.

Ao analisarem os efeitos antibacterianos do OTT contra E. coli e K. pneumoniae de isolados clínicos humanos, Andrade et al. (2016) optaram pela técnica de microdiluição em placas, utilizando o OTT em diversas concentrações, também utilizando como emulsificante Tween 80 a $0,5 \%$ além do indicador resazurina a $0,01 \%$ na determinação da CIM. Para avaliação do potencial antimicrobiano, fez-se uso tanto do OTT quanto do seu principal componente de forma isolada, o terpinen-4-ol, este último apresentando-se efetivo na inibição do crescimento bacteriano a uma concentração de $0,1 \%$, enquanto a do OTT ficou em $0,5 \%$, se aproximando do valor encontrado no presente estudo.

Utilizando microrganismos distintos, Lee et al. (2013) testaram OTT contra Propionibacterium acnes e Staphylococcus aureus em modelo animal, utilizando óleo de jojoba no preparo da emulsão, sugerindo como ideal a aplicação de concentrações inferiores a 5\% de OTT em produtos à base do composto, uma vez que foi observada irritação na pele dos ratos, provocada principalmente pelos compostos terpinen-4-ol e 1,8-cineol do OTT, sugerindo ainda que a concentração de $2 \%$ é ideal para inibição do crescimento bacteriano in vivo.
Empregando a nanoencapsulação, Flores et al. (2013) concluíram que OTT tem sua volatilidade diminuída consideravelmente, fornecendo proteção às propriedades do óleo. Low et al. (2013) verificaram a atividade antimicrobiana do OTT aliado a íons de prata através de lipossomas como sistema de liberação controlada. Em suspensão de Pseudomonas aeruginosa e Staphylococcus aureus, os autores observaram que o sistema coloidal é melhor para utilização em formulações tópicas e semissólidas, com liberação do ativo em locais específicos e prevenindo ou reduzindo possíveis reações de sensibilidade. Promove também um aumento de permanência do ativo, potencializando a sua ação tópica, podendo ser empregada para desenvolvimento de fármacos em tecnologias futuras.

Sakkas et al. (2016) testaram a atividade antimicrobiana in vitro de cinco óleos essenciais, entre eles o OTT, utilizando a técnica de macrodiluição frente a cepas de E. coli ESBL, $K$. pneumonia ESBL, $K$. pneumonia $\mathrm{KPC}$, Acinetobacter baumannii e $P$. aeruginosa, isolados de pacientes de um Hospital da Grécia. As concentrações de 0,125 a $4 \%$ foram testadas e a CIM determinada entre $0,5 \%$ a $0,75 \%$, para os microrganismos. Embora não sendo idênticas às do presente experimento, as atividades inibitórias pelos óleos essenciais podem variar de acordo com a origem da cepa bacteriana, influenciando os resultados do potencial das plantas para o desenvolvimento de novos antimicrobianos.

Em seu estudo, Ogbaini-Emovon et al. (2015) testaram a atividade in vitro de OTT em isolados multirresistentes, incluindo E. coli $\mathrm{ESBL}$ e $K$. pneumonia KPC. As emulsões foram preparadas com óleo de oliva e OTT nas concentrações de 1,5 a $10 \%$ e testadas pela técnica de disco-difusão. Cada disco foi impregnado com $10 \mu \mathrm{L}$ do OTT nas três concentrações testadas. Concluiu-se que esses microrganismos demonstraram notável susceptibilidade ao óleo, com formação de halos entre $10 \mathrm{~mm}$ e $36 \mathrm{~mm}$, divergindo deste estudo.

Os óleos essenciais têm o potencial de alterar tanto a permeabilidade como a função das proteínas da membrana celular, bloqueando suas atividades normais. Embora esse mecanismo de ação já tenha sido relatado, deve-se considerar que as moléculas químicas presentes nos extratos naturais das plantas são diversas. Logo, a 
atividade de inibição do crescimento bacteriano não pode ser atribuída a um único mecanismo de ação, mas a diversos mecanismos bioquímicos e estruturais da célula bacteriana e de seus componentes internos e externos, que afetam as funções da membrana celular e/ou de outras organelas (NAZZARO et al., 2013). Assim, a identificação dos exatos compostos que exercem efeitos bactericidas torna-se um pré-requisito para otimizar seu potencial uso terapêutico (SAKKAS et al., 2016).

Todos os isolados analisados mostraram-se susceptíveis a alguma das concentrações de óleo testadas. A CIM variou conforme a metodologia empregada e acredita-se que tal variação tenha relação com as características bioquímicas do óleo essencial.

Ao se comparar a CIM dos isolados multirresistentes com as cepas padrões, pode-se inferir que o mecanismo de resistência aos antibióticos é independente da sensibilidade aos terpenos, possivelmente pelo mecanismo de ação distinto.

As emulsões do óleo essencial de Melaleuca alternifolia inibiram o crescimento das bactérias multirresistentes, conforme observado no método da macrodiluição em tubo e Spot-on-the-lawn. A cepa hospitalar de Escherichia coli produtora de ESBL mostrou-se a cepa mais sensível, o que permite descrever o potencial antibacteriano do óleo, que deverá ser avaliado em estudos futuros como agente de controle.

\section{Agradecimentos}

À biomédica Dr ${ }^{\mathrm{a}}$ Mayara C. Onishi por ceder os isolados multirresistentes.

\section{Referências}

ABELA, N.; BORG, M. A. Impact on hand hygiene compliance following migration to a new hospital with improved resources and the sequential introduction of World Health Organization recommendations. American Journal of Infection Control, New York, v. 40, n. 8, p. 737-741, 2012.

AIRES, C. A. M.; PEREIRA, P. S.; DE ARAÚJO, C. F. M.; CHAGAS, T. P. G.; OLIVEIRA, J. C. R.; BUONORA, S. N.; ALBANO, R. M.; CARVALHO-ASSEF, A. P. D.; ASENSI, M. D. Multiclonal expansion of Klebsiella pneumoniae isolates producing NDM-1 in Rio de Janeiro, Brazil. Antimicrobial Agents and
Chemotherapy, Washington, v. 61, n. 4, p. e01048-16, 2017.

ALVES, M. de M.; LEAL, G. S.; SADOYAMA, A. dos S. P.; FERNANDES, E. G. V.; GOMIDE, M.. D. A.; SILVEIRA, A. O. S. M.; AIRES, R. S. P. O controle de infecção hospitalar como indicador para qualidade no serviço de saúde. In: SIMPÓSIO DE METODOLOGIAS ATIVAS - INOVAÇÕES PARA O ENSINO E A APRENDIZAGEM NA EDUCAÇÃO BÁSICA E SUPERIOR \& SIMPÓSIO DO MESTRADO PROFISSIONAL EM GESTÃO ORGANIZACIONAL, III 2017. Anais... São Paulo: Editora Edgard Blücher, 2017. Disponível em: <http://www.proceedings. blucher.com.br/article-details/25391>.

ANDRADE, B. F. M. T.; LEAL, G. S.; SADOYAMA, A. dos S. P.; FERNANDES, E. G. V.; GOMIDE, M.. D. A.; SILVEIRA, A. O. S. M.; AIRES, R. S. P. The antibacterial effects of Melaleuca alternifolia, Pelargonium graveolens and Cymbopogon martinii essential oils and major compounds on liquid and vapor phase. Journal of Essential Oil Research, Carol Stream, v. 28, n. 3, p. 227-233, 2016.

BEZERRA CRISPIM, G. J.; DE LACERDA, M. C. R. N. Análise da ação bacteriolítica da Melaleuca alternifolia nas principais bactérias de interesse médico. Ensaios e Ciência: Ciências Biológicas, Agrárias e da Saúde, Valinhos, v. 18, n. 2, p. 67-75, 2014.

BRASIL - MINISTÉRIO DA SAÚDE. AGÊNCIA NACIONAL DE VIGILâNCIA SANITÁRIA; SANITÁRIA. Resolução-RDC no 20, de 5 de maio de 2011. Brasília: Diário Oficial da União. Disponível em: <http://www.anvisa.gov.br/sngpc/Documentos201 2/RDC 20 2011.pdf $>$.

BROLUND, A. Overview of ESBL-producing Enterobacteriaceae from a Nordic perspective. Infection Ecology \& Epidemiology, Uppsala, v. 4, n. 1, p. 24555, 2014.

CLSI - CLINICAL AND LABORATORY STANDARDS INSTITUTE. M100 Performance Standards for Antimicrobial Susceptibility Testing. Wayne: [s.n.]. 2017. Disponível em: $<$ Www.clsi.org $>$.

DAIFAS, D. P.; SMITH, J. P.; BLANCHFIELD, B.; SANDERS. G.; AUSTIN, J. W.; KOUKOUTISIS, J. Effects of mastic resin and its essential oil on the growth of proteolytic Clostridium botulinum. International Journal of Food Microbiology, Summit-Argo, v. 94, n. 3, p. 313-322, 2004.

DAMATO, J. R. G. Avaliação da eficácia antimicrobiana de sabonetes contendo óleo essencial de Melaleuca alternifolia versus triclosan versus clorexidina e o impacto na adesão à higienização das mãos pelo efeito aromaterápico. 2015. 187 f. Tese (Doutorado em Enfermagem na Saúde do Adulto) Universidade de São Paulo, São Paulo. 2015.

DOI, Y.; IOVLEVA, A.; BONOMO, R. A. The ecology of extendedspectrum $\beta$-lactamases (ESBLs) in the developed world. Journal of Travel Medicine, Oxford, v. 24, n. suppl. 1, p. S44-S51, 2017.

DUTRA, R. C.; CAMPOS, M. M.; SANTOS, A. R. S.; CALIXTO, J. B. Medicinal plants in Brazil: pharmacological studies, drug discovery, challenges and perspectives. Pharmacological Reserarch, Milano, v. 112, p. 4-29, 2016.

FLORES, F. C.; DE LIMA, J. A.; RIBEIRO, R. F.; ALVES, S. H.; ROLIM, C. M. B.; BECK. R. C. R. Antifungal activity of 
nanocapsule suspensions containing tea tree oil on the growth of Trichophyton rubrum. Mycopathologia, Dordrecht, v. 175, n. 3-4, p. 281-286, 2013.

GE, Y.; GE, M. Distribution of Melaleuca alternifolia essential oil in liposomes with Tween 80 addition and enhancement of in vitro antimicrobial effect. Journal of Experimental Nanoscience, London, v. 11, n. 5, p. 345-358, 2016.

GOBBO-NETO, L.; LOPES, N. P. Plantas medicinais: fatores de influência no conteúdo de metabólitos secundários. Química Nova, São Paulo, v. 30, n. 2, v. 374-381, 2007.

GNATTA, J. R. Comparação da eficácia antimicrobiana de sabonetes contendo óleo essencial de Tea Tree (Melaleuca alternifolia) e triclosan na higienização de mãos artificialmente contaminadas. 2012. 144 f. Dissertação (Mestrado em Enfermagem na Saúde do Adulto) - Universidade de São Paulo, São Paulo. 2012.

INTERNATIONAL ORGANIZATION FOR STANDARDIZATION. ISO 4730:2017 - Essential oil of Melaleuca, terpinen-4ol type (Tea Tree oil). 2017. Disponível em: <https://www.iso.org/ standard/69082.html>.

LEAL, P. M. Ação antimicrobiana de compostos majoritários presentes em óleos essenciais sobre bactérias causadoras de infeç̧ões hospitalares. 2013. 45 f. Monografia (Graduação em Ciências Biomédicas) - Universidade Estadual Paulista, Botucatu. 2013.

LEE, C.-J.; CHEN, L. W.; CHEN, L. G.; CHANG, T. L.; HUANG, C. W.; HUANG, M. C.; WANG, C. C. Correlations of the components of tea tree oil with its antibacterial effects and skin irritation. Journal of Food and Drug Analysis, Taipé, v. 21, n. 2, p. 169-176, 2013.

LOW, W. L.; MARTIN, C.; HILL, D. J.; KENWARD, M. A. Antimicrobial efficacy of liposome-encapsulated silver ions and tea tree oil against Pseudomonas aeruginosa, Staphylococcus aureus and Candida albicans. Letters in Applied Microbiology, Malden, v. 57, n. 1, p. 33-39, 2013.

NASCIMENTO, P. F. C.; NASCIMENTO, A. C.; RODRIGUES, C. S.; ANTONIOLLI, A. R.; SANTOS, P. O.; JÚNIOR, A. M. B.; TRINDADE, R. C. Atividade antimicrobiana dos óleos essenciais: uma abordagem multifatorial dos métodos. Revista Brasileira de Farmacognosia, Curitiba, v. 17, n. 1, p. 108-113, 2007.

NAZZARO, F.; FRATIANNI, F.; DE MARTINO, L.; COPPOLA, R.; DE FEO, V. Effect of essential oils on pathogenic bacteria. Pharmaceuticals, Basel, v. 6, n. 12, p. 1451-1474, 2013.

NUNES, A. S. F.; DE LIMA, I. S.; OSÓRIO, R. L.; DE ABREU, A. P. L.; DOS SANTOS, B. H. C.; LIMA, E. O.; SILVA FILHO, E. C.; FERREIRA, J. H. L.; BARRETO, H. M. Efeito do óleo essencial de Ocimum basilicum L. na resistência aos aminoglicosídeos em Staphylococus aureus. Boletim Informativo Geum, Teresina, v. 5, n. 4, p. 31, 2014.

OGBAINI-EMOVON, E.; SCHUSTER, H.; WAZE, J.; KALU, E. I. In vitro antimicrobial activity of commercially available Melaleuca alternifolia (Tea Tree) oil on some selected clinical pathogens. British Journal of Pharmaceutical Research, London, v. 5, n. 3, p. 202-208, 2015.
OPAS/OMS - ORGANIZAÇÃO PAN-AMERICANA DE SAÚDE; ORGANIZAÇÃO MUNDIAL DA SAÚDE. OMS publica lista de bactérias para as quais se necessitam novos antibióticos urgentemente. 2017. Disponível em: <https://www.paho.org/bra/ index.php?option $=$ com_content $\&$ view $=$ article $\&$ id $=5357:$ oms publica-lista-de-bacterias-para-as-quais-se-necessitam-novosantibioticos-urgentemente $\&$ Itemid $=812>$.

OSTROSKY, E. A.; MIZUMOTO, M. K.; LIMA, M. E.; KANEKO, T. M.; NISHIKAWA, S. O.; FREITAS, B. R. Métodos para avaliação da atividade antimicrobiana e determinação da concentração mínima inibitória (CMI) de plantas medicinais. Revista Brasileira de Farmacognosia, Curitiba, v. 18, n. 2, p. 301-307, 2008.

PEREIRA, E. L.; OLIVEIRA, A. F. A. A produção de antibióticos por processos fermentativos aeróbios. Revista da Universidade Vale do Rio Verde, Três Corações, v. 14, n. 2, p. 1058-1078, 2016. RODRIGUES, T. S.; DOS SANTOS, A. M. R.; LIMA, P. C.; MOURA, M. E. B.; GOIANO, P. D. O. L.; FONTINELE, D. R. S. Resistência bacteriana a antibióticos na Unidade de Terapia Intensiva: revisão integrativa. Revista Prevenção de Infecção e Saúde, Teresina, v. 4, p. 1-17, 2018.

SAKKAS, H.; GOUSIA, P.; ECONOMOU, V., SAKKAS, V., PETSIOS, S.; PAPADOPOULOU, C. In vitro antimicrobial activity of five essential oils on multidrug resistant Gram-negative clinical isolates. Journal of Intercultural Ethnopharmacology, Wilmington, v. 5, n. 3, p. 212-218, 2016.

SARTO, M. P. M.; JUNIOR, G. Z. Atividade antimicrobiana de óleos essenciais. Revista UNINGÁ Review, Maringá, v. 20, n. 1, p. 98-102, 2014.

SEFIDKON, F.; ABBASI, K.; JAMZAD, Z.; AHMADI, S. The effect of distillation methods and stage of plant growth on the essential oil content and composition of Satureja rechingeri Jamzad. Food Chemistry, Reading, v. 100, n. 3, p. 1054-1058, 2007.

SEIBERT, G.; HÖRNER, R.; MENEGHETTI, B. H.; RIGHI, R. A.; FORNO, N. L. F. dal; SALLA, A. Nosocomial infections by Klebsiella pneumoniae carbapenemase producing enterobacteria in a teaching hospital. Einstein, São Paulo, v. 12, n. 3, p. 282-286, 2014.

SILVA, J. P. L.; DUARTE-ALMEIDA, J. M.; PEREZ, D. V.; FRANCO B. D. G. M. Óleo essencial de orégano: interferência da composição química na atividade frente à Salmonella enteritidis. Ciência e Tecnologia de Alimentos, Campinas, v. 30, p. 136-141, 2010.

TAKARADA, K.; KIMIZUKA, R.; TAKAHASHI, N.; HONMA, K.; OKUDA, K.; KATO, T. A comparison of the antibacterial efficacies of essential oils against oral pathogens. Oral Microbiology and Immunology, Nova Jersey, v. 19, n. 1, p. 6164, 2004 